\title{
Mitral ring annuloplasty relieves tension of the secondary but not primary chordae tendineae in the anterior mitral leaflet
}

\author{
Sten Lyager Nielsen, MD, PhD, DMSc, ${ }^{\mathrm{a}}$ Mads Lomholt, MD, PhD, ${ }^{\mathrm{a}}$ Peter Johansen, $\mathrm{PhD},{ }^{\mathrm{a}}$ \\ Soeren B. Hansen, MD, PhD, ${ }^{\mathrm{a}}$ Niels Trolle Andersen, $\mathrm{PhD},{ }^{\mathrm{b}}$ and John Michael Hasenkam, MD, DMSc ${ }^{\mathrm{a}}$
}

\begin{abstract}
Objective: Mitral ring annuloplasty is routinely applied as an adjunct procedure in reconstructive surgery on the mitral valve leaflets or chordae tendineae. It is assumed that mitral ring annuloplasty relieves tensile stress on the repaired valve tissue and thereby improves the durability of the procedure, but the indication is disputable. We sought to study the effect of mitral ring annuloplasty on the tension of the primary and secondary chordae tendineae of the anterior mitral valve leaflet in vivo.
\end{abstract}

\begin{abstract}
Methods: In 17 adult pigs miniature chordal force transducers were sutured to the 2 major fixing primary chordae and the 2 strut secondary chordae of the anterior leaflet. Baseline measurements were accomplished. After randomization, one group $(\mathrm{n}=10)$ underwent a mitral ring annuloplasty (Carpentier-Edwards Classic, $28 \mathrm{~mm}$; Edwards Lifesciences, Irvine, Calif), and the second group $(n=7)$ served as controls and underwent a sham operation. Simultaneous recordings of chordae tendineae tension and hemodynamics and echocardiographic assessment of anterior leaflet occlusion area were acquired at baseline and after the mitral ring annuloplasty/sham operation.
\end{abstract}

Results: Mitral ring annuloplasty caused a significant reduction of the anterior leaflet occlusion area $(1.85 \pm 0.16$ vs $\left.4.63 \pm 0.37 \mathrm{~cm}^{2}\right)$ and the tension of the secondary chordae $(0.33 \pm 0.06$ vs $0.67 \pm 0.12 \mathrm{~N})$ but did not affect the tension of the primary chordae $(0.24 \pm 0.07$ vs $0.17 \pm 0.06 \mathrm{~N})$. The sham procedure had no effect on these variables.

Conclusions: In normal porcine hearts mitral ring annuloplasty primarily relieves stress on the anterior leaflet belly rather than the leading edge. Mitral ring annuloplasty might therefore protect repairs of the central portion of the anterior leaflet and secondary chordae but not repairs that solely involve the anterior leaflet's leading edge and adjacent chordae. (J Thorac Cardiovasc Surg 2011;141:732-7)

Mitral valve repair is uniformly favored over mitral valve replacement in almost all mitral valve pathologies, except those of ischemic cause. ${ }^{1}$ Remodeling mitral ring annuloplasty (MRA) is routinely applied as an adjunct procedure to mitral valve repair. MRA reduces the area of the dilated annulus, prevents future dilatation, and facilitates a good surface of leaflet coaptation. Furthermore, it is assumed that the reduction of the occlusion area of the mitral leaflets protects leaflet repairs and reinforces suture lines after leaflet resections because load and tension on the adjoining structures are reduced.

In recent years, replacement of chordae tendineae with expanded polytetrafluoroethylene sutures has gained increasing popularity in the surgical community. ${ }^{2,3}$ The goal of

From the Department of Cardiothoracic and Vascular Surgery and the Institute of Experimental Clinical Research, ${ }^{a}$ Aarhus University Hospital-Skejby, Aarhus, Denmark; and the Department of Biostatistics, ${ }^{\mathrm{b}}$ Faculty of Health Sciences, Aarhus University, Aarhus, Denmark.

Supported by the Danish Heart Association (grants no. 00-1-2-22-22792 and 98-2-569-22658).

Disclosures: Authors have nothing to disclose with regard to commercial support.

Received for publication Jan 5, 2010; revisions received April 22, 2010; accepted for publication May 17, 2010; available ahead of print June 25, 2010.

Address for reprints: Sten Lyager Nielsen, MD, PhD, DMSc, Department of Cardiothoracic and Vascular Surgery, Aarhus University Hospital-Skejby, Brendstrupgaardsvej 100, 8200 Aarhus N, Denmark (E-mail: lyager@ki.au.dk).

$0022-5223 / \$ 36.00$

Copyright (c) 2011 by The American Association for Thoracic Surgery doi:10.1016/j.jtcvs.2010.05.011 the approach is to preserve leaflet tissue and resuspend or replace leading-edge chordae to restore a good surface of leaflet coaptation and thereby ensure satisfactory function of the mitral valve.

In this light unrestrictive use of MRA irrespective of annular and left ventricular size and repair technique has been debated because a good surface of leaflet coaptation can be accomplished by resuspending the leading leaflet edge with chordal replacement without MRA. Finite computer models have demonstrated a nonuniform stress distribution of the mitral leaflets, with high stress on the belly of the anterior leaflet and very low stress on the leaflet's leading edge in the area of coaptation. ${ }^{4}$ In vivo experiments have shown 3-fold higher tension of the secondary than of the primary (marginal) chordae, ${ }^{5}$ indicating that the secondary chordae are load bearing and relieve systolic stresses on the belly of the mitral leaflets, whereas the primary chordae adjust leaflet apposition at closure and might be protected by compressive forces between the leaflets in the area of leaflet coaptation (Figure 1). Accordingly, MRA might protect leaflet repairs and reinforce suture lines on the central portion of the mitral leaflets and the secondary chordae, whereas repairs that solely involve the mitral leaflet's leading edge and adjacent chordae might be adequately protected by a good surface of leaflet coaptation. 


\section{Abbreviations and Acronyms \\ $\mathrm{A}_{\mathrm{AML}}=$ occlusional area of the anterior mitral valve leaflet \\ $\mathrm{A}_{\mathrm{MA}}=$ total mitral annular area \\ $\mathrm{MRA}=$ mitral ring annuloplasty}

In this experimental study we hypothesize that MRA reduces the occlusional area of the anterior mitral valve leaflet $\left(\mathrm{A}_{\mathrm{AML}}\right)$ and that tension of the adjoining chordae is subsequently reduced. The aim of the present study was therefore to study the effect of MRA on the tension of the primary and secondary chordae tendineae of the anterior leaflet in the beating porcine heart. We decided to focus on chordal tension of the anterior leaflet because this leaflet covers a larger area of the mitral orifice and is more mobile than the posterior leaflet during opening and closure; this is especially true after (rigid) MRA, which might "freeze" the posterior leaflet and leave the anterior leaflet as a monocusp mitral valve.

\section{MATERIALS AND METHODS}

\section{Animals and Surgical Preparation}

Twenty-two mixed Yorkshire and Danish Landrace pigs with a body weight of $80 \mathrm{~kg}$ comprised the study population. Two animals were excluded on sternotomy because of pericarditis. Three animals could not be weaned from cardiopulmonary bypass. The remaining 17 animals were randomized to one of 2 groups: group 1 , the MRA group $(\mathrm{n}=10)$, and group 2, the sham-operated control group $(n=7)$. One pig in the MRA group was subsequently excluded because of flawed left ventricular pressure recordings.

The animals were bred at our laboratory farm. Animal handling was performed in accordance with the guidelines of the Danish Committee of Animal Experimentation under the Department of Justice, and this institution approved the study. The animals were premedicated at the animal farm before transportation to the laboratory on the day of the operation. On arrival to the laboratory, endotracheal intubation was accomplished, and the animals were kept anesthetized during the subsequent operation and study period by means of continuous infusion of $8 \mathrm{mg} \cdot \mathrm{kg}^{-1} \cdot \mathrm{h}^{-1}$ ketamine, $3 \mathrm{mg}$ $\mathrm{kg}^{-1} \cdot \mathrm{h}^{-1}$ fentanyl, and $1 \mathrm{mg} \cdot \mathrm{kg}^{-1} \cdot \mathrm{h}^{-1}$ midazolam. The right carotid artery and the jugular vein were surgically exposed, and intravascular sheaths were mounted to ease insertion of fluid-filled pressure catheters. The heart was exposed through a median sternotomy. After aortic crossclamping, the heart was arrested by means of administration of cold crystalline cardioplegic solution (St Thomas Hospital solution no. 1) in the aortic root supplemented by slushed ice around the epicardium.

The mitral valve was exposed on the arrested heart through a left atriotomy. Chordal force transducers were mounted on the 2 major fixing primary chordae and the 2 strut secondary chordae of the anterior leaflet. Approximately 15 2-0 Ethibond sutures (Ethicon, Inc, Somerville, NJ) with felt pledgets were attached on the atrial side of the annulus. The sutures were left untied in the left atrium and brought out together at one point through the atriotomy, making sure that there was no tension on the sutures. The atriotomy was then closed, with a continuous suture enclosing the annuloplasty sutures into the suture line. Mean aortic crossclamp time was $64 \pm$ 8 minutes. After 30 minutes of reperfusion, the pigs were weaned from cardiopulmonary bypass. After hemodynamic stabilization, the first recording series was performed without the mitral annuloplasty ring in place. Cardiopulmonary bypass was resumed, and while the heat was beating, a rigid
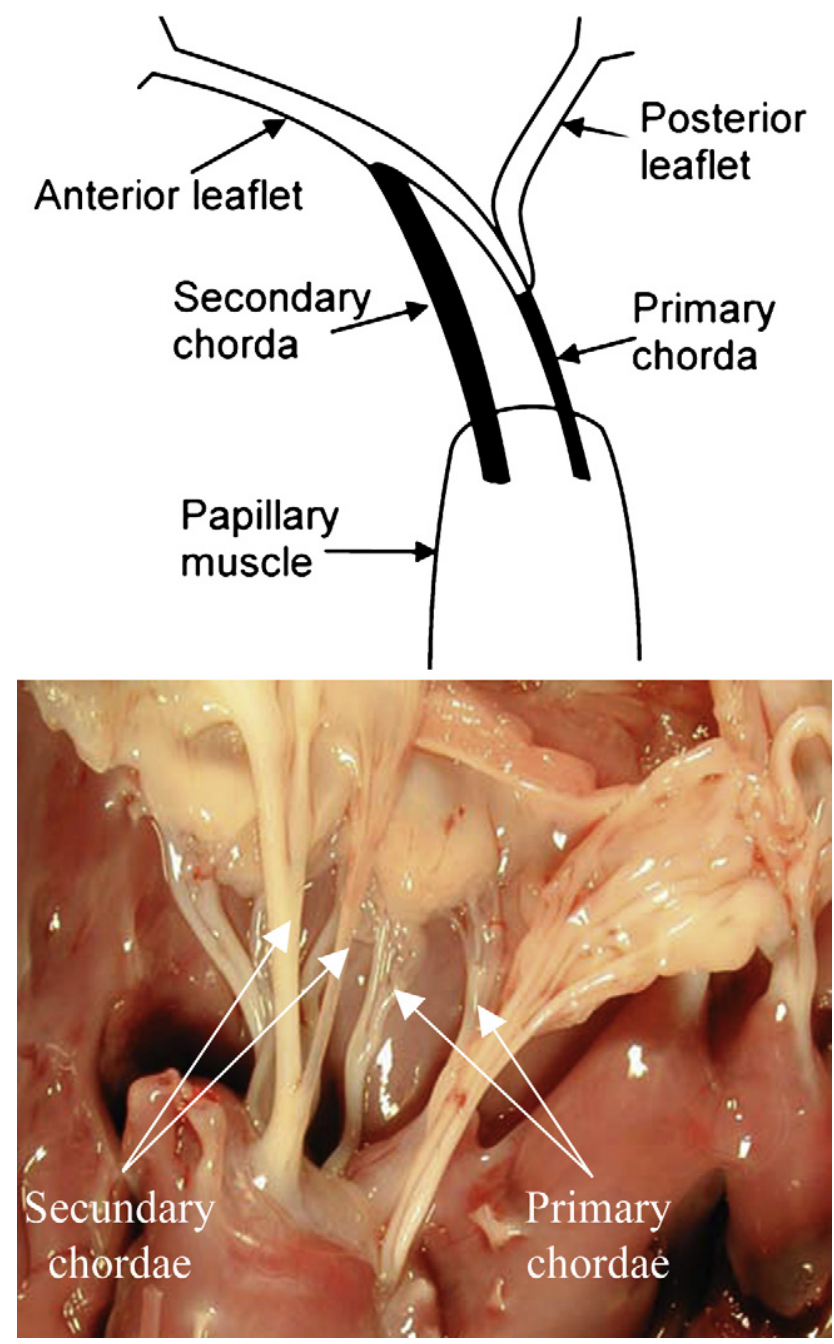

FIGURE 1. Schematic and photographic representation of the mitral valve subvalvular apparatus. Primary chordae tendineae insert in the leading edge and secondary chordae in the leaflet belly.

mitral annuloplasty ring (Carpentier-Edwards Classic, $28 \mathrm{~mm}$; Edwards Lifesciences, Irvine, Calif) was attached to the annulus with the premounted sutures. In the sham group the premounted sutures were left untied and exteriorized through the atriotomy, making sure that there was no tension on the sutures exactly as they were left after the first pump run. The atriotomy was closed. After 15 minutes of reperfusion, the pigs were reweaned from bypass. After hemodynamic stabilization, the recordings were repeated.

\section{Data Acquisition}

Measurements of chordal tension and hemodynamic parameters and echocardiographic recordings were conducted before and after MRA. Sham-operated animals underwent similar surgical procedures, excluding ring implantation, and recordings were likewise made before and after the sham operation. Before each recording series, mitral valve competence was verified by means of color flow Doppler echocardiographic analysis.

Chordal force measurements. Dedicated miniature C-shaped force transducers were mounted on the 4 individual chordae in the anterior leaflet (Figures 1 and 2). A strain indicator (Model 2021; Measurement Group, Inc, Raleigh, NC) was used to operate the transducer. Further details on the construction and function of the transducer have been 


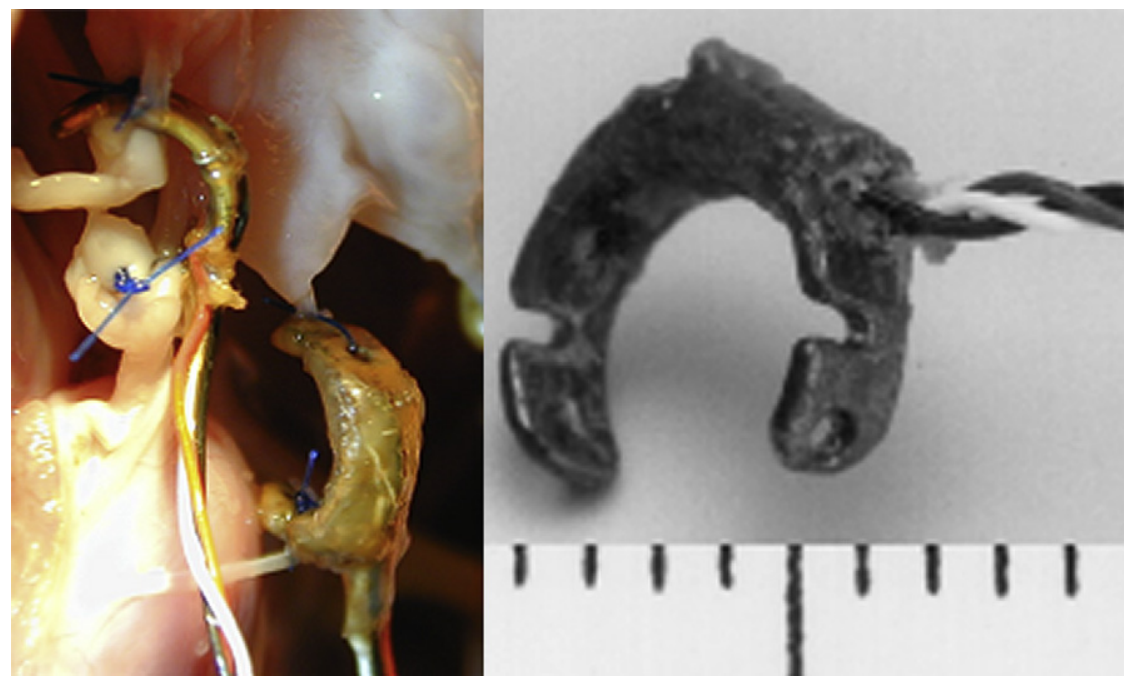

FIGURE 2. Miniature chordal force transducers were mounted on the chordae tendineae. Ruler units are shown in centimeters.

described previously. ${ }^{6}$ The leads from the transducers were exteriorized together with the left ventricular pressure catheter through a purse-string suture on the apex of the heart.

Hemodynamics. A microtip pressure catheter (SPC-350MR; Millar Instruments, Houston, Tex) recorded left ventricular and left atrial pressures. A conventional fluid-filled pressure catheter system recorded arterial pressure, which was further monitored online by using a Sirecust bedside monitor (401-1; Siemens, Berlin, Germany). All signals, including chordal tension, were recorded on a data recorder (XR-510; TEAC, Tokyo, Japan) for subsequent offline analysis.

Echocardiography. Two-dimensional echocardiographic recordings from 6 rotated left ventricular apical views were acquired by means of epicardial echocardiographic analysis with an ultrasound scanner (System Five; Vingmed, Horten, Norway) equipped with a 5-MHz transesophageal probe. The probe was placed manually behind the pericardium of the left atrium in the open chest to ensure optimal acoustic contact. The 6 rotated apical views $\left(0^{\circ}, 30^{\circ}, 60^{\circ}, 90^{\circ}, 120^{\circ}\right.$, and $\left.150^{\circ}\right)$ were acquired with arrested ventilation to avoid motion artifacts. Digital cineloop images along with the electrocardiograms were downloaded to a computer for offline analysis facilitated by commercially available software (EchoPAC version 5.4, Vingmed).

\section{Data Analysis}

All recorded analog signals were converted to digital data through an analog/digital converter; the sampling frequency was $400 \mathrm{~Hz}$ (AT-MIO16-E2; National Instruments, Austin, Tex) by using dedicated software developed in LabView (National Instruments). Zero adjustment of the chordal force transducers was confirmed at the end of prolonged vena caval occlusion, when the chordae were slackened. The maximum chordal tension and corresponding left ventricular pressure were depicted manually in 3 representative heart cycles during caval occlusion. Linear regression (least-squares method) was applied to identify the equation representing the relationship between chordal tension and the independent variable of left ventricular pressure. Chordal tension was then normalized for left ventricular pressure before and after intervention. The resulting chordal tension was presented as the mean of the 2 secondary and 2 primary chordae, respectively.

Mitral valve geometry was analyzed at midsystole. Midsystole was defined as the time of the closest approach between the mitral leaflet coaptation point and the mitral annular plane and corresponded to peak left ventricular pressure and peak chordal tension. The 6 rotated imaging planes partitioned the mitral annulus and the anterior leaflet into 12 individual "pie slices," the areas of which were summed to yield total mitral annular area $\left(\mathrm{A}_{\mathrm{MA}}\right)$ and $\mathrm{A}_{\mathrm{AML}}$, respectively. ${ }^{7}$ Coaptation length between the anterior and posterior leaflets was measured in a 2-chamber long-axis view. Left ventricular end-diastolic area $\left(A_{\text {LVED }}\right)$ and left ventricular end-systolic area $\left(A_{L V E S}\right)$ were assessed from a long-axis 4-chamber view. Ejection fraction (EF) was estimated as follows: $E F=\frac{A_{L V E D}-A_{L V E S}}{A_{L V E D}}$.

\section{Statistical Analysis}

Data are presented as means \pm standard errors of the mean. Differences in chordal tension, coaptation length, $\mathrm{A}_{\mathrm{MA}}$, and $\mathrm{A}_{\mathrm{AML}}$ before and after MRA/sham operation were compared by means of a paired 2-tailed $t$ tests. Comparison between the MRA and sham groups with respect to change from baseline of chordal tension and $\mathrm{A}_{\mathrm{AML}}$ was performed by means of an unpaired 2-tailed $t$ test.

The authors had full access to the data and take responsibility for its integrity. All authors have read and agree to the manuscript as written. Data acquisition, statistical analysis, and manuscript preparation were done independently of any sources of funding.

\section{RESULTS}

Hemodynamic and echocardiographic data were obtained for the 16 pigs, although data from 1 or more of the 4 chordae were missing in some animals. Hemodynamic data before and after MRA/sham operation are shown in Table 1.

Figure 3 shows an example of the tension in the anterolateral and posteromedial primary and secondary chordae throughout the cardiac cycle in relation to left ventricular pressure before and after MRA. The time course of chordae tendineae tension typically followed the left ventricular pressure and exhibited a regular pattern. The time elapsed until maximum tension in the primary chordae was always recorded as shorter than the time until maximum tension in the secondary chordae (mean, $153 \pm 6.1$ vs $171 \pm 6.5$ $\mathrm{ms}$ ), although the difference was not statistically significant. Minimum tension of the 4 chordae occurred in early diastole. From middiastole, the tension of the secondary chordae 
TABLE 1. Ejection fraction, left ventricular pressure, and heart rate before and after MRA/sham operation

\begin{tabular}{lcccc}
\hline & Before MRA (mean \pm SEM) & After MRA (mean \pm SEM) & $\begin{array}{c}\text { Before sham operation } \\
\text { (mean } \pm \text { SEM) }\end{array}$ & $\begin{array}{c}\text { After sham operation } \\
(\text { mean } \pm \text { SEM) }\end{array}$ \\
\hline Heart rate (beats/min) & $110 \pm 5(\mathrm{n}=9)$ & $112 \pm 5(\mathrm{n}=9)$ & $115 \pm 20(\mathrm{n}=7)$ & $118 \pm 18(\mathrm{n}=7)$ \\
LVP $(\mathrm{mm}$ Hg) & $83 \pm 4(\mathrm{n}=9)$ & $88 \pm 8(\mathrm{n}=9)$ & $85 \pm 6(\mathrm{n}=7)$ & $76 \pm 4(\mathrm{n}=7)$ \\
EF $(\%)$ & $0.4 \pm 0.2(\mathrm{n}=9)$ & $0.4 \pm 0.3(\mathrm{n}=9)$ & $0.4 \pm 0.2(\mathrm{n}=7)$ & $0.4 \pm 0.2(\mathrm{n}=7)$ \\
\hline
\end{tabular}

All values are presented as means \pm standard errors of the mean. There was no statistically significant difference before and after mitral ring annuloplasty/sham operation (paired $t$ test). The change in hemodynamic variables from baseline was not significantly different after mitral ring annuloplasty compared with that seen after the sham operation (unpaired $t$ test). $M R A$, Mitral ring annuloplasty; $S E M$, standard error of the mean; $L V P$, left ventricular pressure; $E F$, ejection fraction.

tended to increase to a peak diastolic value at end-diastole before initiation of left ventricular contraction. The tension of the primary chordae only changed slightly during diastole. This time course of the chordae tendineae tension and relationship to left ventricular pressure did not change after MRA.

Left ventricular pressure and ejection fraction did not significantly change from baseline after MRA/sham operation, and the change from baseline was not significantly different between MRA and the sham operation.

$\mathrm{A}_{\mathrm{MA}}$ and $\mathrm{A}_{\mathrm{AML}}$ were significantly reduced after MRA, and the coaptation length was significantly increased (Table 2). The sham operation had no effect on these variables. Accordingly, the change in $\mathrm{A}_{\mathrm{MA}}$ and $\mathrm{A}_{\mathrm{AML}}$ and coaptation length from baseline was significantly different after MRA compared with that seen after the sham operation (change in
$\mathrm{A}_{\mathrm{MA}}:-4.14 \pm 0.53$ vs $0.98 \pm 0.84 \mathrm{~cm}^{2}$; change in $\mathrm{A}_{\mathrm{AML}}$ : $-2.78 \pm 0.30$ vs $\left.0.60 \pm 0.57 \mathrm{~cm}^{2} ; P>.001\right)$.

Tension in the secondary chordae was significantly reduced in the MRA group. Tension in the primary chordae did not change significantly in animals undergoing MRA. The sham operation had no effect on these variables (Table 2). The change in secondary chordal tension in the MRA group was significantly different from the change in the sham group $(-0.34 \pm 0.13$ vs $0.07 \pm 0.11 \mathrm{~N}$, $P<.001)$. Neither the absolute nor relative change in primary chordal tension in the MRA group was statistically significantly different from the change in the sham group $(-0.06 \pm 0.04$ vs $0.04 \pm 0.06 \mathrm{~N}, P=.70)$. There was no difference in tension between the 2 secondary or between the 2 primary chordae of each papillary muscle. This was true both before and after intervention.
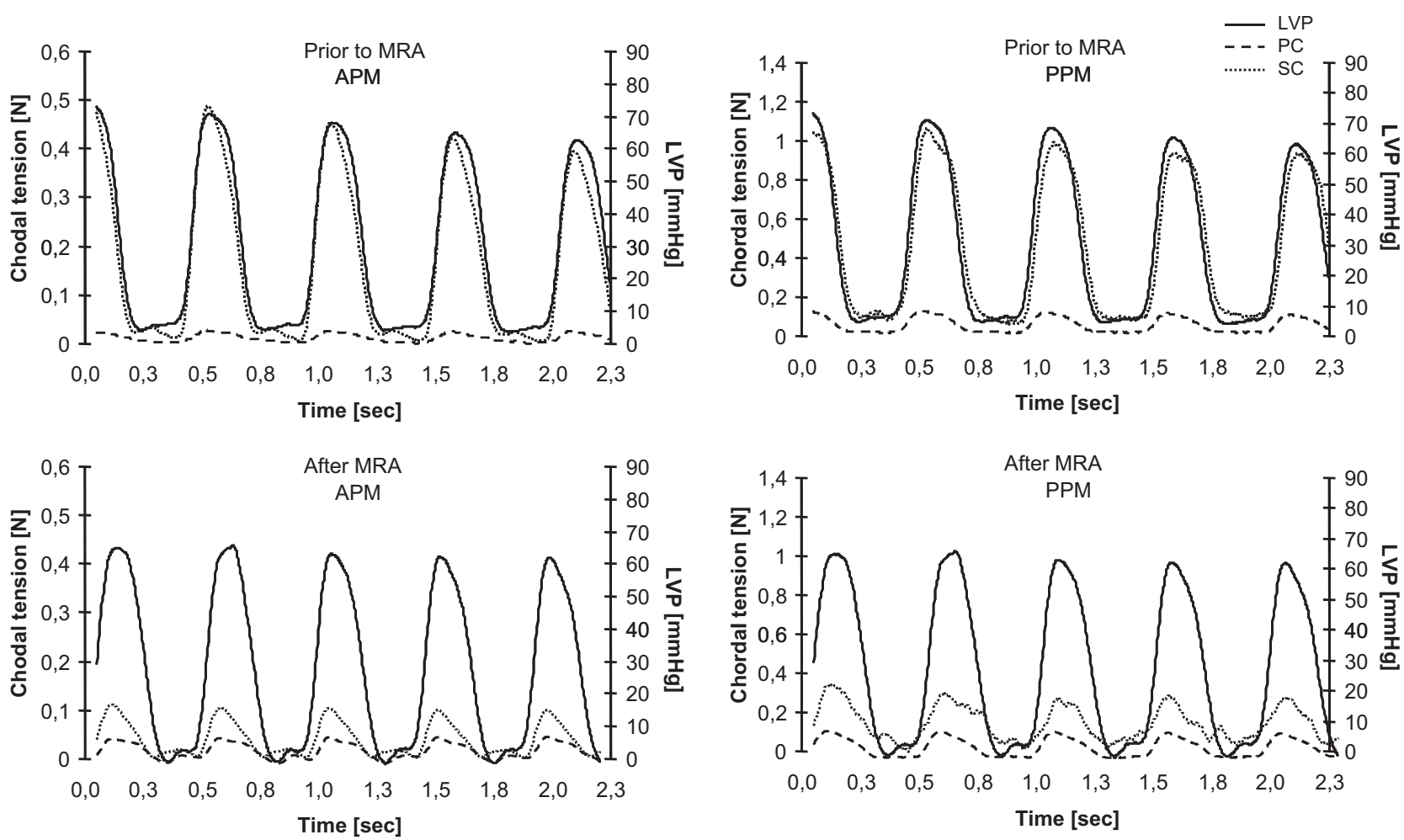

FIGURE 3. Tension of primary (dashed line) and secondary (dotted line) chordae from anterolateral (APM) and posteromedial ( $P P M)$ papillary muscle in relation to left ventricular pressure (black line) before (top) and after (bottom) mitral ring annuloplasty. Data represent 1 animal. 
TABLE 2. Chordal tensions before and after MRA/sham operation

\begin{tabular}{lcccccc}
\hline & $\begin{array}{c}\text { Before MRA } \\
(\text { mean } \pm \text { SEM) }\end{array}$ & $\begin{array}{c}\text { After MRA } \\
(\text { mean } \pm \text { SEM) }\end{array}$ & $\begin{array}{c}\boldsymbol{P} \text { value } \\
(\text { paired } \boldsymbol{t} \text { test })\end{array}$ & $\begin{array}{c}\text { Before sham } \\
\text { operation }(\text { mean } \pm \text { SEM) }\end{array}$ & $\begin{array}{c}\text { After sham } \\
\text { operation }(\text { mean } \pm \text { SEM) }\end{array}$ & $\begin{array}{c}\boldsymbol{P} \text { value } \\
(\text { paired } \boldsymbol{t} \text { test })\end{array}$ \\
\hline $\mathrm{A}_{\mathrm{MA}}\left(\mathrm{cm}^{2}\right)$ & $7.43 \pm 0.61(\mathrm{n}=9)$ & $3.29 \pm 0.68(\mathrm{n}=9)$ & .0001 & $6.28 \pm 0.99(\mathrm{n}=7)$ & $7.27 \pm 0.72(\mathrm{n}=7)$ \\
$\mathrm{A}_{\mathrm{AML}}\left(\mathrm{cm}^{2}\right)$ & $4.63 \pm 0.37(\mathrm{n}=9)$ & $1.85 \pm 0.16(\mathrm{n}=9)$ & .0001 & $3.94 \pm 0.47(\mathrm{n}=7)$ & $4.54 \pm 0.57(\mathrm{n}=7)$ \\
$\mathrm{CL}(\mathrm{cm})$ & $0.54 \pm 0.09(\mathrm{n}=9)$ & $0.75 \pm 0.08(\mathrm{n}=9)$ & .05 & $0.40 \pm 0.08(\mathrm{n}=7)$ & $0.49 \pm 0.13(\mathrm{n}=7)$ \\
$\mathrm{F}_{\mathrm{SC}}(\mathrm{N})$ & $0.67 \pm 0.12(\mathrm{n}=9)$ & $0.33 \pm 0.06(\mathrm{n}=9)$ & .03 & $0.61 \pm 0.09(\mathrm{n}=7)$ & $0.68 \pm 0.13(\mathrm{n}=7)$ \\
$\mathrm{F}_{\mathrm{PC}}(\mathrm{N})$ & $0.17 \pm 0.06(\mathrm{n}=6)$ & $0.24 \pm 0.07(\mathrm{n}=6)$ & .42 & $0.22 \pm 0.09(\mathrm{n}=5)$ & $0.18 \pm 0.08(\mathrm{n}=5)$ & .43 \\
\hline
\end{tabular}

There are missing data for the primary chordae in the second, sixth, and seventh animals in the mitral ring annuloplasty group and of the primary chordae in the first and fifth animals in the sham group. MRA, Mitral ring annuloplasty; SEM, standard error of the mean; $A_{M A}$, mitral annular area; $A_{A M L}$, anterior mitral leaflet occlusion area; $C L$, coaptation length between the anterior and posterior leaflets; $F_{S C}$, secondary chordal tension; $F_{P C}$, primary chordal tension.

\section{DISCUSSION}

The resulting pressure force acting on the anterior leaflet is the product of $\mathrm{A}_{\mathrm{AML}}$ and the transmitral pressure difference in systole. ${ }^{7}$ Accordingly, a reduction in $\mathrm{A}_{\mathrm{AML}}$, as achieved by MRA, reduces the resulting pressure force acting on the anterior leaflet and reduces the counter-balancing forces distributed through the chordae tendineae. It is believed that the increase in the coaptation area between the anterior and posterior mitral valve leaflets contributes to relieve tension of the primary chordae.

The present study showed that MRA reduced $\mathrm{A}_{\mathrm{AML}}$ and increased coaptation length between the leaflets. The reduction in $\mathrm{A}_{\mathrm{AML}}$ was accompanied by a decrease in secondary chordae tension but not in primary chordae tension. This observation indicates that the secondary chordae are the principal load-bearing chordae that oppose the pressure force of the transmitral pressure difference acting on the leaflet surface area, whereas the role of the primary chordae seems to be different. These observations challenge the necessity of remodeling MRA as an adjunct procedure to repair techniques that aim at restoring a good surface of coaptation by adding new chordae to the leading leaflet edge, especially in an era of early intervention, even in asymptomatic patients with preserved left ventricular function (and less/reversible mitral annular dilatation). These observations might also make allowances for minimally invasive techniques that aim at restoring a good surface of leaflet coaptation, such as transapical chordal replacement, ${ }^{8}$ without remodeling ring annuloplasty.

The time course of primary and secondary chordal tension in early systole was not identical. Although the difference was not statistically significant, it is noteworthy that the primary chordae in all animals reached their maximum tension before the secondary chordae. In accordance with this observation, a theoretical analysis ${ }^{9}$ of the timing and distribution of tensile stress on the chordal apparatus at mitral valve closure has proposed that the primary chordae were prone to reach peak tension before the secondary chordae in the early phase of mitral valve closure before apposition of the leaflet tips. The role of the primary chordae was related to free-edge leaflet control during mitral leaflet coaptation to ensure proper apposition rather than opposing pressure force. The peak tension of the primary chordae might therefore be unaffected by the reduction of the occlusional leaflet area induced by the MRA, as observed in the present study.

Recently, a number of experimental studies have suggested that the secondary chordae of the anterior leaflet enhance left ventricular wall systolic function and are a component of valvular-ventricular interaction, corroborating the theory of differential function of the chordae. Obadia and colleagues ${ }^{10}$ showed that when the primary chordae were cut in isolated beating pig hearts, severe mitral insufficiency would occur, although with preserved left ventricular function. In contrast, when secondary chordae were cut, significant left ventricular dysfunction resulted, although the mitral valve remained competent. Furthermore, Nielsen and associates ${ }^{11}$ showed regional left ventricular systolic dysfunction, and recently, Rodriguez and coworkers ${ }^{12}$ demonstrated both disturbed global left ventricular function and altered left ventricular geometry after cutting the secondary chordae in ovine models without mitral valve repair.

In normal pig hearts, Lomholt and associates ${ }^{5}$ showed that secondary chordae carried a tension more than 3 -fold higher than that seen in primary chordae during systole, which demonstrates a principal force transmission through the secondary chordae during left ventricular ejection. The influence of $\mathrm{A}_{\mathrm{AML}}$ and left ventricular pressure on secondary chordal tension in the present study does not exclude an important role for these chordae on left ventricular systolic function, but our findings corroborate that this valvular-ventricular force transmission is mediated through an intricate coupling to the mitral leaflets. It is obviously only speculative and beyond the scope of this study to discuss whether the observed decrease in peak secondary chordae tension after MRA could have a potential negative effect on left ventricular systolic performance; at least, MRA did not affect any hemodynamic standard parameters.

Our findings are, of course, only valid for the anterior leaflet. However, similar findings could be anticipated in the posterior leaflet because the distribution and chordal architecture are similar. ${ }^{13}$ Finite computer simulations ${ }^{14}$ even suggest that MRA to treat annular dilatation causes the most noticeable reduction of the posterolateral aspect of the annulus and results in higher stress reduction of the posterior leaflet than of the anterior leaflet. 


\section{CONCLUSIONS}

The present study indicates that MRA of the normal nondilated mitral annulus in pigs relieves stress on the anterior leaflet belly rather than on the leading edge. Therefore MRA might protect mitral repairs on the central portion of anterior leaflet and secondary chordae but might not protect repairs that solely involve the anterior leaflet's leading edge and adjacent chordae that are principally protected by a good surface of leaflet coaptation.

\section{Perspective}

These observations challenge the necessity of remodeling MRA as an adjunct procedure to repair techniques that aim at restoring a good surface of coaptation by adding new chordae to the leading leaflet edge, especially in an era of early intervention, even in asymptomatic patients with preserved left ventricular function (and less/reversible mitral annular dilatation). These observations might also make allowance for minimally invasive techniques that aim at restoring a good surface of leaflet coaptation, such as transapical chordal replacement, ${ }^{8}$ without remodeling ring annuloplasty.

\section{Study Limitations}

Data were obtained in an acute, open-chest setting immediately after a long and complicated cardiac surgical procedure, which is far from normal clinical circumstances. Despite the fact that porcine mitral valves have been identified as a suitable model for human conditions, the experiments were performed in normal animal hearts without the pathophysiological deformation that can accompany chronic mitral regurgitation in patients. It is reasonable to assume that unfolding of the leaflet coaptational zone because of annular dilatation alters the force distribution through the primary chordae and consequently the effect of remodeling MRA. It is plausible (but not shown in this study) that annular dilatation as a part of the disease process might reduce the coaptation zone between the anterior and posterior mitral leaflets. Obliterating the surface of leaflet coaptation might expose the thinner and weaker primary chordae to increased pressure load. As a consequence, primary chordal tension would increase significantly, and this would explain why the most likely chordae to rupture are the primary chordae. Thus in cases with annular dilatation, MRA would be expected to reduce the primary chordae tension and stabilize the leading edge of the valve.

Our findings only apply for the 4 specific chordae evaluated, a relevant limitation because it is likely that chordal tension varies according to the insertion site on the mitral leaflets. Constant random motion of the chordal force transducers within the left ventricular cavity reduced the signal/ noise ratio and might have drown very low-amplitude signals from the primary chordae.

\section{References}

1. Gillinov AM, Wierup PN, Blackstone EH, Bishay ES, Cosgrove DM, White J, et al. Is repair preferable to replacement for ischemic mitral regurgitation? $J$ Thorac Cardiovasc Surg. 2001;122:1125-41.

2. David TE, Omran A, Armstrong S, Sun Z, Ivanov J. Long-term results of mitral valve repair for myxomatous disease with and without chordal replacement with expanded polytetrafluoroethylene sutures. J Thorac Cardiovasc Surg. 1998;115: 1279-85.

3. Perier P, Hohenberger W, Lakew F, Batz G, Urbanski P, Zacher M, et al. Toward a new paradigm for the reconstruction of posterior leaflet prolapse: midterm results of the "respect rather than resect" approach. Ann Thorac Surg. 2008; 86:718-25.

4. Salgo IS, Gorman JH III, Gorman RC, Jackson BM, Bowen FW, Plappert T, et al. Effect of annular shape on leaflet curvature in reducing mitral leaflet stress. Circulation. 2002;106:711-7.

5. Lomholt M, Nielsen SL, Hansen SB, Andersen NT, Hasenkam JM. Differential tension between secondary and primary mitral chordae in an acute in-vivo porcine model. J Heart Valve Dis. 2002;11:337-45.

6. Nielsen SL, Soerensen DD, Libergren P, Yoganathan AP, Nygaard H. Miniature c-shaped transducers for chordae tendineae force measurements. Ann Biomed Eng. 2004;32:1050-7.

7. Nielsen SL, Nygaard H, Mandrup L, Fontaine AA, Hasenkam JM, He S, et al Mechanism of incomplete mitral leaflet coaptation-interaction of chordal restraint and changes in mitral leaflet coaptation geometry. Insight from in vitro validation of the premise of force equilibrium. J Biomech Eng. 2002;124:596-608.

8. Bajona P, Katz WE, Daly RC, Zehr KJ, Speziali G. Beating-heart, off-pump mitral valve repair by implantation of artificial chordae tendineae: an acute in vivo animal study. J Thorac Cardiovasc Surg. 2009;137:188-93.

9. Nazari S, Carli F, Salvi S, Banfi C, Aluffi A, Mourad Z, et al. Patterns of systolic stress distribution on mitral valve anterior leaflet chordal apparatus. A structural mechanical theoretical analysis. J Cardiovasc Surg (Torino). 2000;41:193-202.

10. Obadia JF, Casali C, Chassignolle JF, Janier M. Mitral subvalvular apparatus: different functions of primary and secondary chordae. Circulation. 1997;96:3124-8.

11. Nielsen SL, Timek TA, Green GR, Dagum P, Daughters GT, Hasenkam JM, et al Influence of anterior mitral leaflet second-order chordae tendineae on left ventricular systolic function. Circulation. 2003;108:486-91.

12. Rodriguez F, Langer F, Harrington KB, Tibayan FA, Zasio MK, Cheng A, et al Importance of mitral valve second-order chordae for left ventricular geometry, wall thickening mechanics, and global systolic function. Circulation. 2004; 110(suppl 1):II1 15-22.

13. Kunzelman KS, Cochran RP, Verrier ED, Eberhart RC. Anatomic basis for mitral valve modelling. J Heart Valve Dis. 1994;3:491-6.

14. Kunzelman KS, Reimink MS, Cochran RP. Flexible versus rigid ring annuloplasty for mitral valve annular dilatation: a finite element model. J Heart Valve Dis. 1998;7:108-16. 